\title{
The wrong vaccine: custody time limits and loss of liberty during Covid-19
}

\author{
Luke Marsh* \\ Chinese University of Hong Kong, Hong Kong \\ *Author e-mail: luke.marsh@cuhk.edu.hk
}

(Accepted 10 April 2021)

\begin{abstract}
In a context where the criminal courts have been drastically affected by coronavirus, this paper seeks to demonstrate that the presumption of innocence risks becoming a further casualty of Covid-19. It will argue that prolonged pre-trial detention of unconvicted defendants has been sanctioned by the senior judiciary under the Custody Time Limit (CTL) Regulations. Following a series of important CTL decisions, a universal position of the senior judiciary, one supportive of government, is emerging: despite the case backlog resulting in defendants facing trial delays of unknown length, the exceptional circumstances of the pandemic which the executive faces, amounts to 'good cause' to extend CTLs. It will be argued that the correct approach for courts to follow is that that they must hear evidence that justifies why no court rooms are available before using that to mandate extensions. It will be further contended that these farreaching decisions came from the senior judiciary's perceived need to mop up the problem posed by widespread refusals to extend CTLs, raising questions as to their ability to act independently of political pressure.
\end{abstract}

Keywords: Covid-19; custody time limits; judicial independence; criminal justice; defendants

\section{Introduction}

Criminal trials across England and Wales continue to face lengthy adjournments. The pressures placed upon an already creaking system in the grip of a global health crisis has resulted in widespread incapacity that poses a threat to fundamental protections underpinning the criminal process. This paper focuses on a significant inroad to liberty faced by unconvicted defendants (legally innocent people), which has been overlooked in the rush to explain how government is keeping 'victims and the public safe ${ }^{1}$ as criminal courts confront the ever-growing case backlog. ${ }^{2}$

A series of recent decisions on Custody Time Limits (CTLs) has illuminated this issue as one worthy of closer examination. CTLs are set by regulations, stipulating the maximum time limit that an accused person can be remanded in custody pending trial. Whereas a routine extension to a CTL might seem unexceptional, the onset of Covid-19 led to the unprecedented phenomenon of blanket-wide extensions being granted to the prosecution, with the result that many criminally accused who found bail was refused faced the prospect of indefinite pre-trial detention. ${ }^{3}$

\footnotetext{
${ }^{1}$ Government Press Release on CTLs (6 September 2020), published online, available at https://www.gov.uk/government/ news/suspected-criminals-held-for-longer-as-criminal-courts-recovery-plan-announced (last accessed 11 May 2021).

${ }^{2}$ At the time of writing, the total backlog runs in excess of 550,000 cases. For a breakdown of crown court case numbers, see below.

${ }^{3}$ In Justice under Lockdown (25 June 2020) the watchdog Fair Trials reported on its survey of the criminal justice system carried out between March and May 2020. Among its findings was confirmation that CTLs were 'being extended routinely' due to delays.

(c) The Author(s), 2021. Published by Cambridge University Press on behalf of The Society of Legal Scholars. This is an Open Access article, distributed under the terms of the Creative Commons Attribution licence (http://creativecommons.org/licenses/by/4.0/), which permits unrestricted re-use, distribution, and reproduction in any medium, provided the original work is properly cited.
} 
Whereas the CTL framework is normally applicable to a situation where there is a fixed trial date at some point in the future, a root problem has been the issue of there being no trial dates available to courts on account of reduced capacity following Covid-19 related restrictions. This distinction is an important, albeit under-appreciated, matter because applications to extend custody are being made in the dark as to when the crisis (meaning here both Covid-related and court backlog) might end.

Prior to the pandemic the CTL regime, pursuant to the Prosecution of Offences (Custody Time Limits) Regulations $1987^{4}$ (CTL Regulations), permitted pre-trial detention up to 182 days (six months). ${ }^{5}$ This was increased to 238 days (eight months) by way of temporary amendment to the CTL Regulations on 28 September $2020 .^{6}$

Although there are considerable doubts about the conscionability of this recent development, ${ }^{7}$ this paper primarily seeks to explore the way in which courts have grappled with the tension between the terms and objectives of the CTL regime and its applicability to what, at points, risked becoming an indefinite detention process. It is argued here that a prevailing de facto extension of CTLs functions as a panacea for the government's struggles as it works out how to reduce the case backlog. Its failures in this regard have resulted in a disturbingly draconian pre-trial detention process. More controversially, it will be argued that decision-making on CTL extensions has been constructed in a way to ensure the continuation of the government's Covid-19 criminal justice agenda is guaranteed (ie not undermined) under the aegis of senior judges, with concerning repercussions for the independence of the judiciary.

Ultimately, this paper contests that a procedural regime which prioritises protection of alleged victims and the public from a perceived risk of 'dangerous criminals ${ }^{8}$ threatens to divert attention from the safeguard that provides more overarching protection to each and every one of us: the presumption of innocence.

\section{Detained defendants' pre-trial protections}

When a defendant awaits trial his or her remand into custody engages Article 5(3) of the European Convention on Human Rights (ECHR) which states that: 'Everyone arrested or detained [for trial] ... shall be entitled to trial within a reasonable time or to release pending trial'.

Despite the wording of the article appearing to present these two outcomes as alternatives, the European Court of Human Rights (ECtHR) has determined that an accused person is entitled to trial within a reasonable period and release pending trial unless the prosecuting authorities advance relevant and sufficient reasons for refusing bail. ${ }^{9}$

The tension therefore arising in the context of criminal trials is that between a defendant's right under Article 5(3) ECHR, and the prosecution's insistence (where sanctioned by the court) that the

\footnotetext{
${ }^{4}$ SI $1987 / 299$.

${ }^{5} 56$ days in the magistrates' court.

${ }^{6}$ The Prosecution of Offences (Custody Time Limits) (Coronavirus) (Amendment) Regulations 2020, SI 2020/953 is in force until 28 June 2021. Where a defendant is committed for trial on an 'either way' case the increase is from 112 days to 168 days.

${ }^{7}$ Discussed below.

${ }^{8}$ Above $\mathrm{n} 1$.

${ }^{9}$ Wemhoff $v$ Germany (1979-80) 1 EHRR 55. The meaning of 'reasonable period' requires an assessment in each case according to its special features': P Van Dijk et al (eds) Theory and Practice of the European Convention on Human Rights (Intersentia, $5^{\text {th }}$ edn, 2018) p 481. In this regard, the European authorities demonstrate a wide range of time periods where pre-trial detention was held not to be in breach of Art 5(3). For example, a detention period slightly in excess of four years in Wv Switzerland (ECtHR 26 January 1993, App No 14379/88) was considered reasonable, whereas other cases have gone in the opposite direction: Shishkov v Bulgaria (ECtHR 9 January 2003, App No 38822/97) and Belchev $v$ Bulgaria (ECtHR 8 April 2004, App No 39270/98) ruling seven months and three weeks, and four months and fourteen days, respectively, to be in violation of Art 5(3). Despite these disparities in length of lawful detention, Van Dijk et al (ibid) posit that three factors are paramount when assessing the 'reasonableness of the duration of the procedure': 'the complexity of the case, the conduct of the detainee and the conduct of the authorities'. Further, '[i]n case the length of a period spent in detention on remand does not appear to be essentially attributable either to the complexity of the case or to the applicant's conduct and the authorities did not act with the necessary promptness, Article 5(3) is violated' (emphasis added).
} 
accused remain in custody until a trial can commence. ${ }^{10}$ The Prosecution of Offences Act (POA) 1985, s 22(3) seeks to resolve the tension between the need to detain some defendants pending trial and their rights under the ECHR by enabling the Court to extend the CTL. The power to extend a CTL is provided for by the POA 1985, s 22(3), which states:

The appropriate court may, at any time before the expiry of a time limit imposed by the regulations, extend or further extend that limit; but the court shall not do so unless it is satisfied-

(a) that the need for the extension is due to-

(i) the illness or absence of the accused, a necessary witness, a judge or a magistrate;

(ii) a postponement which is occasioned by the ordering by the court of separate trials in the case of two or more accused or two or more offences; or

(iii) some other good and sufficient cause; and

(b) that the prosecution has acted with all due diligence and expedition. ${ }^{11}$

No attempt is made here to discuss those cases where it is argued that the prosecution has failed to act with due diligence and expedition. As such, it is unnecessary to address s 22(3)(b). Rather, the discussion herein relates to the provision addressing 'good and sufficient cause' to extend CTLs (s 22(3)(a) (iii)). In the context of this paper, this refers to cases which are trial-ready, ie due to begin, but delayed, and the cause of the delay is a conglomeration of Covid-19 restrictions and the measures the government has taken to reduce their adverse impact upon the system. Consequently, s 22(3)(a)(i) and (ii) also have no separate application here. On the CTL principles themselves, it needs to be borne in mind that beyond any finding that there is good and sufficient cause to extend, a free-standing discretion (' $m a y$ ') is still available to the judge. Thus, fulfilment of the POA criteria is not conclusive of refusal. ${ }^{12}$ This residual discretion is an important feature to note in light of subsequent developments arising from the official response to Covid-19 that will be touched upon.

In making an assessment under s 22(3)(a)(iii) as to whether the time a defendant can be detained pre-trial should be extended, a judge must consider the fundamental principles underpinning the provisions in the POA 1985. ${ }^{13}$ These are: (i) to ensure that the periods for which unconvicted defendants are held in custody are as short as is reasonably and practically possible; (ii) to oblige the prosecution to prepare cases for trial with due diligence and expedition; and (iii) to give the court power to control any extension of the maximum period for which any defendant may be held awaiting trial.

Despite this guiding framework, the current challenge facing any judge who is making a determination on CTLs under the POA 1985, is the vexed question as to when a trial can be reasonably accommodated in light of the voluminous case backlog that has handicapped courts in getting cases to trial before CTLs expire.

To put the problem in context, before Covid-19 struck there was a backlog of some 37,500 Crown Court cases. It is estimated that there are more than 46,000 such cases awaiting trial. ${ }^{14}$ In ordinary circumstances then, the backlog was already placing enormous pressure upon the system, with many cases likely to experience a protracted journey through the courts. While Covid-19 has undoubtedly elevated the backlog figure, it is a non-sequitur to say the pandemic is the cause of the case

\footnotetext{
${ }^{10}$ For example, it is trite law that in almost every case of an allegation of murder the court is likely to be satisfied there are substantial grounds for believing that the defendant, if released on bail (whether subject to conditions or not) would fail to surrender to custody, given the potential sentence.

${ }^{11}$ Emphasis added.

${ }^{12}$ Although a fine point, it is important to spell this out, as the language is capable of fusing those two aspects.

${ }^{13}$ As explained by Lord Bingham CJ when he expounded these principles in the context of emphasising the presumption of liberty set out in the ECHR in $R v$ Manchester Crown Court, ex p McDonald [1999] 1 Cr App R 409.

${ }^{14}$ According to data from the Office of National Statistics, available online.
} 
logjam, which far pre-dated the worldwide health emergency. ${ }^{15}$ Despite this, the government ${ }^{16}$ has implemented major alterations to the criminal process, ${ }^{17}$ including CTLs, by statutory instrument and without proper parliamentary debate. ${ }^{18}$ However, far from 'ensuring that justice continues to be delivered', ${ }^{19}$ these measures, which rely on support from the senior judiciary, will augment the challenge of case disposal and weaken the position of defendants.

\section{The official response to Covid}

On 17 March 2020 Lord Burnett LCJ issued a public message which spoke to the major disruption which lay ahead:

Trials in the Crown Court present particular problems in a fast-developing situation because they require the presence in court of many different participants including the judge, the jury, a defendant, lawyers and witnesses as well as staff. Given the risks of a trial not being able to complete, I have decided that no new trial should start in the Crown Court unless it is expected to last for three days or less. All cases estimated to last longer than three days listed to start before the end of April 2020 will be adjourned. These cases will be kept under review...

Following this guidance, on 23 March 2020, the Lord Chief Justice pronounced that no new trials would commence until further notice. ${ }^{20}$ Whilst the LCJ's statement neutralised the defence argument that protection of the right to a fair and speedy trial ought, at least, to trigger the start of the case, the issue as to CTLs remained very much alive with trials now in abeyance.

In this regard, the 'Coronavirus Crisis Protocol for the Effective Handling of Custody Time Limit Cases' (the Protocol) was issued by the senior presiding judge, HM Courts and Tribunals Service and the Crown Prosecution Service on 7 April 2020, ${ }^{21}$ which sought to give concrete guidance to judges tasked with safeguarding a defendant's right not to be detained for periods longer than the legal limit. While the protocol did not have the force of law, ${ }^{22}$ its purpose was set out in the following language: 'to set a temporary framework during the Coronavirus pandemic for the efficient and expeditious handling of cases that involve a Custody Time Limit (CTL). It does not create legal obligations or restrictions on (any) party'. ${ }^{23}$ Although the Protocol was also said not to 'override independent judicial discretion' its effect was precisely that, when it stated:

The coronavirus pandemic is an exceptional situation and the adjournment of CTL trials as a consequence of government health advice and of directions made by the Lord Chief Justice amounts to good and sufficient cause to extend the custody time limit. ${ }^{24}$

Following its issuance, the Protocol had a dual effect. First, the language realistically deprived judges of the entitlement to find that there was no 'good' and 'sufficient' cause to extend a CTL. Secondly, the

\footnotetext{
${ }^{15}$ The statistics (ibid) show the current backlog was exceeded each year from 2005 to 2011 . They approached 50,000 in 2013, and exceeded this number in 2014 and 2015.

${ }^{16}$ Although the government has been eager to portray coronavirus as the source of all its problems, this argument has been debunked elsewhere: see M McConville and L Marsh 'Criminal justice in a time of Covid-19: paralysis and prognosis' (2020) 170 New Law Journal 7906.

${ }^{17}$ In this same vein, the Justice Secretary and Lord Chancellor Robert Buckland QC reanimated proposals to remove the right to jury trial although these appear to have stalled following resistance from the legal profession.

${ }^{18}$ As permitted by powers in the Coronavirus Act 2020, which came into effect on 25 March. The Lord Chancellor was, in effect, able to unilaterally extend CTL limits with far reduced scope for scrutiny from the opposition.

${ }^{19}$ Above $\mathrm{n} 1$.

${ }^{20}$ This was subsequently endorsed by the Lord Chancellor.

${ }^{21}$ An earlier draft of the Protocol, with some differences not material here, was released on 1 April 2020.

${ }^{22}$ Its precise standing as 'authority' is unclear.

${ }^{23}$ Para 2.

${ }^{24}$ Para 15
} 
content of the Protocol, with its omnibus ruling, also heavily influenced the exercise of a judge's residual discretion so as to truly scupper a favourable exercise of it. The inevitable corollary of tying judges to this government advice was, to adopt the language of the ECtHR, ${ }^{25}$ quasi-automatic prolongation of detention. ${ }^{26}$ In other words, an extension of the CTL was deemed to be the correct approach to take in every case. It is not clear then how this judicial diktat was to be reconciled with the Protocol's additional remark that 'every case must be decided on its own merit', especially when the entire purpose of the Protocol was to underscore that the global pandemic is an exceptional situation thereby satisfying the statutory criteria under the POA. Indeed, the likelihood that judicial discretion in such matters would take a backseat is evidenced by the dearth of decisions where an extension was refused in terms that brought it into conflict with the Protocol. ${ }^{27}$ As such, this Protocol encouraged, if not overtly mandated, a non-discretionary approach to CTL extensions in contradistinction to the statutory language of the POA 1985, s 23(3). ${ }^{28}$

While the persuasive force of this approach was arguably greatest while jury trials were prevented from taking place, they partly resumed on 18 May $2020^{29}$ in a limited capacity on account of the need for proceedings to adhere to strict social-distancing. ${ }^{30}$ The Protocol remained in place until 2 September 2020, when the President of the Queen's Bench Division and the Senior Presiding Judge withdrew it on the basis that it was 'out of date and has served its purpose'. Their reasoning largely reflected the fact that jury trials had grown in sufficient number since their recommencement. Despite the situation in Crown Courts having 'changed significantly', judicial leaders were able to give continued effect to the Protocol by pronouncing that it 'reflected much that has become good practice'. On their view '[a]rrangements that have made the listing of CTL extension applications straightforward and convenient will, no doubt, continue, wherever practical'. Crucially, they highlighted '[d]ecisions [as to CTL extensions] will continue to be made ... with the restricted availability of courts an important factor'.

This last point requires underscoring because it endorsed continued detention of unconvicted defendants on the basis of what are essentially administrative considerations, dependent on the availability of resources. Plainly, in ordinary circumstances, this would stand in stark contrast to the protection afforded under Article 5(3) ECHR, and so the government's framing of the Covid-19 situation alongside the criminal courts reception of this situation warrants further examination.

\section{Shifting goal posts}

To minimise the frequency of CTLs being challenged in the courts, the Prosecution of Offences (Custody Time Limits) (Coronavirus) (Amendment) Regulations 2020 ${ }^{31}$ (the Regulations) came into force on 28 September 2020, extending the CTLs in the Crown Court by two months (to 238 days).

In introducing the 'temporary legislation' the government issued a press release on 6 September 2020. Implausibly, it explained that increasing the period of pre-trial detention to nine months, and therefore, the length of the case, was part of a package of measures (termed the 'Criminal Courts

\footnotetext{
${ }^{25}$ When discussing Art 5 ECHR.

${ }^{26}$ Tase $v$ Romania, ECtHR (Third Section) 2008, para 40.

${ }^{27}$ As will be explained, where a pattern of non-extension later occurred (even following the Protocol's withdrawal), the senior judiciary did not hesitate to intervene to counteract its precedential force.

${ }^{28}$ Paragraph 5 would appear to be rendered otiose by actual practice on the ground. It states: 'This Protocol does not override independent judicial discretion and every case must be decided on its own merits. The Protocol contains rules of practice only and the relevant law is unaffected. The judge responsible for deciding each application will apply the law'.

${ }^{29}$ The first socially-distanced trial was at Bristol Crown Court. Trials at the Central Criminal Court recommenced on 1 June 2020.

${ }^{30}$ Consisting of courts being arranged so that no one is less than two metres apart from others, evidence is displayed on screens rather than soft copies being distributed and the use of video-links (where appropriate) for witnesses and defendants.

${ }^{31}$ SI $2020 / 953$.
} 
Recovery Plan') ${ }^{32}$ that would assist in 'reducing delays and delivering speedier justice for all'. ${ }^{33}$ A number of questions flow from this claim. Most prominently, if the Protocol that had been in place since April 'reflected much that has become good practice', and CTL extensions would 'continue to be made on a case by case basis' why was it necessary to sanction a further and universal increase of nearly one third in the duration courts can detain an accused pre-trial? ${ }^{34}$ Not only does this mean that CTLs are being used to incarcerate unconvicted people for far longer than the regime ever envisaged ( $\mathrm{cf}$ 'short as is reasonably and practically possible'), but allowance for two further months of delay undermines the prosecution requirement to 'prepare cases for trial with due diligence and expedition'. It is axiomatic that prosecutorial urgency impacts profoundly upon the ability of the defence to understand and prepare for the scope of the allegation it faces. The relevant maximum custody period is there to alert the Prosecution that time is moving on and areas such as disclosure require prompt attention. The appalling track record of the police ${ }^{35}$ and CPS $^{36}$ in recent years with regard to this aspect of the criminal process does not instil confidence that extended custody periods will therefore lead to speedier justice. In reality, the greater the period in which it has to investigate and prepare its cases, the more inefficient prosecutorial processes are likely to become. ${ }^{37}$

Aside from this increased threat to the fairness of criminal trials, there is a further abiding danger that defendants now face. Although said to be temporary, ${ }^{38}$ the measure to extend CTLs has permanent effect on the liberty of those currently governed by this regime who are subsequently acquitted, for the simple reason there is no recourse available to them for being detained. Compounding this is a heightened risk of wrongful convictions where defendants weigh up the inducement of early release in the event of a confession, a rational calculation in the eyes of those facing potential penalties far less severe than the strictures of indefinite detention. ${ }^{39}$

This curtailing of an accused's liberty, and impinging upon their freedom as to plea, was achieved by way of statutory instrument, shunning ordinary channels of Parliamentary scrutiny. The lack of parliamentary oversight allowed the Justice Secretary to impose the two-month extension to the custody period upon reasoning that is highly questionable. Two reasons to support its introduction were offered. It was said to be necessary because ' $[\mathrm{i}] \mathrm{t}$ addresses the delays to jury trials that have been caused by the pandemic'. This rests on a misdirection as to the provenance of the backlog. Whilst the stoppage of jury trials for less than two months plainly aggravated attempts to tackle the swell of case numbers, courtroom delays are more attributable to longstanding underfunding of the system. ${ }^{40}$

\footnotetext{
${ }^{32}$ The installation of plexiglass screen in courtrooms among them. See COVID-19: Update on the HMCTS response for criminal courts in England \& Wales (September 2020), available online, available at https://assets.publishing.service.gov. uk/government/uploads/system/uploads/attachment_data/file/915493/HMCTS401_recovery_overview_for_crime_WEB.pdf (last accessed 11 May 2021).

${ }^{33}$ Emphasis added.

${ }^{34}$ Paradoxically, the position for convicted persons runs opposite to the position for those unconvicted persons detained in custody. The Court of Appeal in $R v$ Manning [2020] EWCA Crim 592 ruled in April 2020 that judges 'should keep in mind that the impact of a custodial sentence is likely to be heavier during the current emergency than it would otherwise be' (para 41).

${ }^{35}$ See eg W Crisp 'The Met has lost over 1,300 pieces of evidence' (The Times, 5 October 2020).

${ }^{36}$ The inefficiency affecting both organisations is well-documented. To take just one example: 'Judge slams police and CPS for “disgraceful” sentencing delay' BBC News Online, 17 January 2020, available at https://www.bbc.com/news/uk-englandsouth-yorkshire-51147371 (last accessed 11 May 2021). See further eg L Marsh 'Leveson's narrow pursuit of justice: efficiency and outcomes in the criminal process' (2016) 45(1) Common Law World Review 51.

${ }^{37}$ In $R$ (McAuley) v Crown Court at Coventry (Practice Note) [2012] EWHC 680 (Admin), the court reiterated that the existence of a 'limit' in CTLs has 'the collateral benefit that money is not squandered by the unnecessary detention of persons in prison awaiting trial at significant cost to the taxpayer' (para 25).

${ }^{38}$ The use of temporary legislation to restrict liberty when not subject to rigorous parliamentary scrutiny is suspect in and of itself; even more so when it is being used to manage a crisis that is anything but temporary.

${ }^{39}$ This woeful state of affairs mirrors the risks to voluntariness presented by sentence discounts and other financial incentives to plead guilty. See further M McConville and L Marsh Criminal Judges (Cheltenham: Edward Elgar, 2014). For the classic account of pre-trial pressures influencing decisions of accused people see M Feeley The Process of the Punishment (New York: Russell Sage, 1979).

${ }^{40}$ See M Chalkley and A Chalkley's report for the Bar Council: Small Change for Justice - Funding for Justice in England and Wales (2010-2019), July 2020.
} 
Secondly, the government explained the 'moves will protect victims and keep dangerous criminals off our streets'. ${ }^{41}$ As in other areas of the criminal process, ${ }^{42}$ this reasoning not only subverts the foundational principle underpinning custody time limits, ${ }^{43}$ which is to 'protect the liberty of the citizen, assumed at the present stage not to be guilty ${ }^{44}$ but it is also wrongheaded because the explicit priority given to victims ignores that many will be adversely affected by longer delays - some significantly so. ${ }^{45}$ Furthermore, while there will be cases where witness intimidation or the prospect of further violence loom large, these do not represent the majority filtering through the system. In this respect, a less draconian non-custodial approach involving preventative measures, including electronic tags, is surely to be preferred. ${ }^{46}$

\section{A limit too far}

One significant CTL ruling (Young-Williams) ${ }^{47}$ favouring this approach and which coincided with the announcement of the new legislation was heard at Woolwich Crown Court before HHJ Raynor on 8 September 2020.

Its significance lies in the judge's appraisal of two politically sensitive issues. First, whether current systemic problems (ie the backlog and consequent inability to fix a trial date) which necessitate repeat CTL extensions stem from 'a lack of money provided by Parliament'. Secondly, whether the steps proposed by government 'to alleviate the situation appear to have a prospect of success' ${ }^{48}$

Young-Williams involved a 19 year-old defendant charged with several counts of serious drug offences (contrary to s 4(3)(b) and 5(3) of the Misuse of Drugs Act 1971), having an offensive weapon (s 1(1) of the Prevention of Crime Act 1953) and possession of criminal property (cash) (s 329(1)(c) of the Proceeds of Crime Act 2002).

Having been remanded into custody on 23 October 2019, the prosecution sought a first extension of his CTL on 16 April 2020. A second extension was agreed to on 17 June 2020. On 16 July 2020 a third extension was granted until 10 September 2020. A hearing for the prosecution's fourth application to extend the time limit was dealt with on 8 September 2020 at which point the defendant had been in custody for 321 days (amounting to 139 days beyond the custody limit that applied to him under the old rules). ${ }^{49}$

The ruling issued on that date by HHJ Raynor was forthright in its criticism of the government's administration of criminal justice in light of its impact upon the CTL regime, the outcome being that the prosecution's fourth application to extend the custody period was refused and the defendant was released from prison on condition that he wore an electronic tag.

Beyond any affirmation of the principle of individual freedom, the basis upon which Young-Williams was released is notable because the ruling had seismic implications for countless

\footnotetext{
${ }^{41}$ Above $\mathrm{n}$ 1, emphasis added. In $R v$ Tesfa Young-Williams (Woolwich Crown Court, 8 September 2020) HHJ Raynor gave the subtle rebuke: 'I feel sure this must have been in oversight' (para 31).

${ }^{42}$ The Explanatory Note at the end of the Regulations speaks to the disregard for empirical data which has become a hallmark of system-change. It reads: 'A full impact assessment has not been produced for this instrument as no, or no significant, impact on the private, voluntary or public sectors is foreseen'. As further evidence of this information deficit, Fair Trials (above $\mathrm{n} 3$ ) discovered, in response to freedom of information requests, that neither the CPS nor MoJ could provide figures on how many CTL extension applications have been made since March 2020. Nor did the government know how many people had been held in prison beyond the time limit since Covid-19 restrictions were put in place.

${ }^{43}$ In that 'the seriousness of the offence with which the defendant is charged cannot of itself be good and sufficient cause within the section; nor can the need to protect the public': ex p McDonald, above n 13, at 414-415.

${ }^{44}$ As stated by Toulson J sitting in the Crown Court at Winchester in $R v$ Blair and Bryant and $R v$ Taylor (unreported, 7 October 1998), and cited with approval by Bingham CJ in ex $p$ McDonald, above n 13.

${ }^{45}$ S Francis 'Coronavirus: delays to trials “prolong trauma” for victims' (BBC News, 25 September 2020), published online, available at https://www.bbc.com/news/uk-england-54277856 (last accessed 11 May 2021). There is the added risk that victims will melt away through fatigue or discouragement and frustrate the prosecution itself.

${ }^{46}$ Relieving pressure on a prison population (now in excess of 83,000) that is the highest in Europe.

${ }^{47} R$ v Tesfa Young-Williams (Woolwich Crown Court, 8 September 2020).

${ }^{48}$ Ibid, para 22.

${ }^{49}$ Even under the new CTL the defendant had been detained 83 days longer than the allowable limit.
} 
other CTL cases. In declaring that a lack of court capacity (which meant defendants would not face trial until the following year or later) was an unacceptable basis upon which to extend custody time limits, HHJ Raynor had opened a procedural Pandora's box that no doubt gave great anxiety to the Ministry of Justice (MoJ) and HM Courts and Tribunals Service (HMCTS). In future, other defendants approaching the expiration of their CTL would be able to canvass identical arguments when resisting applications to extend, with the upshot that many would be released from detention to await their trial.

To fully appreciate the significance of the judicial intervention that followed, it is necessary to set out the route by which $\mathrm{HHJ}$ Raynor arrived at his decision. Having disregarded the validity of the Protocol that had been issued on 7 April 2020, the judge still held that coronavirus amounted to an 'exceptional situation'. ${ }^{50}$ Judge Raynor then drew a distinction between 'routine' cases and 'exceptional' cases and held that coronavirus, by itself, did not automatically turn the former into the latter. This meant that although system delay had become inbuilt following the pandemic (ie routine), extensions ought not to be allowed for this reason alone. The effect of this ruling was that all future prosecution applications to extend a CTL could no longer exclusively rely on the existence of the virus in arguing there was 'good' and 'sufficient' cause to, as required by s 22(3) POA 1985. It was necessary for any judge to go a step further to examine the evidence 'of what measures MoJ/HMCTS considered and/or actually implemented - so as to justify the non-availability of a trial date'. ${ }^{51}$

In determining whether the balance favoured an extension, the judge explained he was required to weigh up the level (or lack) of funding from the MoJ to tackle the backlog (and provide trials within the CTLs) with the likely efficacy of the government's strategy in place under the umbrella 'recovery plan'. In noting that these issues are interwoven, $\mathrm{HHJ}$ Raynor held the recovery plan was not adequate to meet the crisis.

HHJ Raynor took it upon himself (ie 'in the absence of evidence from a senior MoJ/HMCTS official') $^{52}$ to review the available material, in great detail, of the government's efforts (concrete and in proposal form) to tackle the case backlog, including Nightingale Courts, $£ 80$ million additional expenditure (which he deemed too little) and 1,600 new staff (whose introduction he said was too late). ${ }^{53}$

As to the use of the Nightingale Courts, the judge was hardly inviting controversy by highlighting both the inadequate number on hand, and their ineffectualness. ${ }^{54}$ As to the single emergency court set up in London, HHJ Raynor explained that much of its caseload had merely been diverted from another local court. Accordingly, '[it] was not, for a period, providing any significant additional capacity. ${ }^{55}$

In concluding that there was overarching 'systemic failure', the judge held that the core measures that had been taken by MoJ/HMCTS brought the state into conflict with its obligations under the ECHR, namely its duty to try unconvicted defendants within a reasonable time, irrespective of whether the appropriate test is 'regardless of cost' or even a lesser requirement of 'high cost' or 'cost proportionate to the exceptional situation'.

\footnotetext{
${ }^{50} R v$ Tesfa Young-Williams, above $\mathrm{n} 47$, para 35. In arriving at this conclusion, the learned judge relied upon a ruling from HHJ Laing QC in $R v$ Navarre on 6 August 2020 (para 6).

${ }^{51}$ Ibid, para 37.

${ }^{52} \mathrm{Ibid}$, para 54 . This was in spite of a line of authority (discussed below) which stated that it was incumbent upon the court to hear evidence on oath from the prosecution to justify extending CTLs and not to accept claims from HMCTS on trust that measures it had implemented (or would implement) were adequate to deal with the court situation caused by the health crisis.

${ }^{53} \mathrm{HHJ}$ Raynor also expressed the stated aim of HMCTS of having 250 working court rooms by November that same year as 'too little, too late': $R v$ Tesfa Young-Williams, above $\mathrm{n} 47$, para 47.

${ }^{54}$ To exacerbate the problem the government backtracked on the Lord Chancellor's indication before the justice select committee in June 2020 that 200 Nightingale Courts would be needed. This has transformed into a reduced target of 60 instead. See 'Court capacity still falling short despite increasing demand' (The Times, 8 October 2020).

${ }^{55} R v$ Tesfa Young-Williams, above $\mathrm{n} 47$, para 70.
} 


\section{The 'administration' and 'justice' functions of the judiciary}

Two days prior to Young-Williams, the government announced that it would increase CTLs by two months. As such, the government faced what it no doubt saw as the politically invidious optics of 'dangerous criminals ${ }^{56}$ being released from prison on account of its inability to manage the case backlog. It also had to contend with HHJ Raynor's excoriating judgment on the governmental attempts to manage the criminal justice system during Covid-19. In fact, this represented Judge Raynor's second refusal to extend custody time limits, ${ }^{57}$ although it was not until Young-Williams that media attention was excited. ${ }^{58}$ Unable to shed its ostensible commitment to the independence of the judiciary by intervening directly, the government was able to rely instead on the senior judiciary to push forward its agenda. ${ }^{59}$ The exercise in damage limitation that followed was swift.

Having comported himself with a critical eye over the government's recovery plan, HHJ Raynor's rulings in favour of non-extension were plainly anathema to the message that ' $\mathrm{t}$ ] hroughout the pandemic this government has taken the necessary steps to protect the public while ensuring that justice continues to be delivered'. ${ }^{60}$ Although he had displayed a level of independence in close accordance to the traditional encomium surrounding his judicial role (ie willing to 'stand between the subject and any attempted encroachments on his liberty by the executive ${ }^{61}$ ), HHJ Raynor's involvement with CTL applications was brought to an abrupt end. Not only was the judge stripped of the opportunity to handle the CTL hearing affecting his own trial but all CTL matters thereafter.

In a remarkable chain of events, HHJ Raynor found himself bumped from a hearing scheduled for the following day. ${ }^{62}$ The judge had been due to hear counsel's arguments on a third CTL extension in relation to a different defendant. That case ( $R v P$ and Others $)$ was in the event listed instead for a mention during which it was announced to all parties that a decision had been taken by the Senior Presiding Judge that a High Court judge would be drafted in to hear the CTL extension application instead. $^{63}$

The accelerated nature of his substitution, it is submitted, could only have been brought about by his stance on what he ruled to be bungled and inadequate attempts by government to deliver criminal justice against a background of Covid-19. It also follows that the judge's unsparing appraisal of HMCTS in Young-Williams gave an air of predictability to the likely outcome of any subsequent CTL application he adjudicated upon (especially one the following day which sought to challenge the adequacy of HMCTS' response to date to the global pandemic). Put bluntly, had HHJ Raynor been allowed to hear further applications to extend CTLs, he would have set an ongoing (persuasive

\footnotetext{
${ }^{56}$ Although this stands in contrast to the government's announcement that it would release 4000 prisoners in order to reduce the spread of coronavirus.

${ }^{57} R v$ Graham (5 September 2020) was the first (referred to in Young-Williams).

${ }^{58}$ It was reported but not in the same terms as Young-Williams.

${ }^{59}$ For an account of how government has relied on the senior judiciary to further its policies in other areas of criminal justice, see M McConville and L Marsh The Myth of Judicial Independence - Criminal Justice and the Separation of Powers (Oxford: Oxford University Press, 2020).

${ }^{60}$ Above $\mathrm{n} 1$.

${ }^{61}$ Liversidge $v$ Anderson [1942] AC 206, 244, per Atkin LJ. In a more modern context, European case law reaffirms this: 'Judicial control of interferences by the executive with the individual's right to liberty is an essential feature of the guarantee embodied in Article 5(3), which is intended to minimise the risk of arbitrariness': Brogan v United Kingdom (1989) 11 EHRR 117 para 58. Indeed, HHJ Raynor felt sufficiently excised by the scope for tension with the senior judiciary and/or government that he included a section in his ruling in which he rehearsed his judicial oath (para 89).

${ }^{62}$ Evidently, this was a hostile take-over: C Coleman 'Judge makes formal complaint over Covid custody waits' (BBC News, 11 September 2020), published online, available at https://www.bbc.com/news/uk-england-london-54109098 (last accessed 11 May 2021).

${ }^{63}$ It is worth noting that this course of action was precipitated by HHJ Raynor's closing remark in the Young-Williams ruling that he had received indications almost a month prior that 'all contested CTL extension applications were henceforth to be heard only by members of a small panel of judges at each Crown Court and that Resident Judges were to decide which judges were to be assigned to any such panel' (para 91). Plainly HHJ Raynor understood this shrinking of the judicial pool to apply to future cases, as opposed to current ones, this being a reasonable interpretation on account of him being permitted to adjudicate on time limits in Young-Williams.
} 
albeit non-binding) precedent of releasing defendants out of custody with an impression likely to surface that government was at fault. The implications of other judges adopting this sea-change of opinion towards further extensions would, inevitably, have brought much unwanted public attention to a criminal justice system already in disarray.

When arguments on CTL extensions were eventually heard in $R v P$ and Others, counsel for the defence ventilated a litany of concerns arising from the hurried and 'highly irregular' ${ }^{64}$ removal of HHJ Raynor and the shuffling in of the Presiding Judge of the South East Circuit, Mrs Justice Whipple:

... the change of personnel has occurred because the senior judiciary are unhappy with Judge Raynor's previous decisions, they have an agenda to prevent further judgments from Judge Raynor in the same vein as his previous two, that the senior judiciary is forum-shopping to achieve the result that it wants, that the Lord Chief Justice has entered into a Concordat with the Lord Chancellor in 2004 which engaged the senior judiciary in administration of the criminal justice system, and by signing a foreword to HMCTS’ Updated Recovery Plan in September 2020 alongside the Lord Chancellor has assumed responsibility for that plan.

With this perception openly circulating, ${ }^{65}$ an application by the defence was made for Mrs Justice Whipple to recuse herself from hearing the CTL extension application. Rejecting any suggestion of actual or perceived bias on account of her alleged links to HMCTS, the Presiding Judge refused the application and found herself able to adjudicate the matter with impartiality and objectivity, on the basis of evidence and argument put before [her]'. ${ }^{66}$

Cognisant of the growing 'press and public interest' and that 'the decision in this case has the potential to be of wider interest beyond this case', Whipple J used the occasion to unbuckle any further threat of suggestion that an Executive-Judicial alliance prevented senior judicial criticism of the government's recovery plan:

The recovery plan is not 'my cause'... [it is] right to say that as a Presider I know about the recovery plan, and that I have had contact with HMCTS officials about it. But every judge in the land knows about the recovery plan ... if all these judges were to recuse themselves the system would become unworkable.

Whilst this line of argument may appeal to a pragmatic understanding of the line drawn between judges who are required to rule upon government policy they simultaneously have to administer, it circumvents the more awkward truth that HHJ Raynor's decision, if more widely adopted, would have likely resulted in the CTL regime becoming unworkable.

In light of the inevitable consequences for the defendant of the switching out of Judge Raynor for another more senior judge, and, to rebut the serious but putatively well-founded allegation that the court was 'forum-shopping' the Court's quick judicial replacement required a credible explanation. The only one offered by Whipple J was that 'the SPJ considered this application for CTL extension to be suitable for determination by a High Court Judge, and indeed a High Court Judge with some experience of running the criminal courts gained from being a presider'. ${ }^{67}$

Setting aside the insufficiency of the proposition - one an anathema to ordinary practice expectations - that it is necessary for a High Court judge to deal with a day-to-day application such as a CTL,

\footnotetext{
${ }^{64} R v P$ and Others (Woolwich Crown Court, 14 September 2020), para 15.

${ }^{65}$ Bemusement within the profession over Judge Raynor's removal was overtaken by suspicion that a senior judge had placed pressure upon him to extend the CTL, when he divulged that he had come under the impression he was being subjected to 'improper and undue influence'. HHJ Raynor took the unusual step of disclosing correspondence between himself and the Resident Judge at Woolwich. See T Kirk 'Judge who slammed Ministry of Justice Covid-19 response on collision course with senior judiciary over "improper pressure” claim' (Evening Standard, 10 September 2020).

${ }^{66} R \vee P$ and Others, above n 64, para 18.

${ }^{67}$ Ibid, para 19.
} 
the supplementary reason regarding experience running courts invites closer inspection. Whipple J's underlying claim would appear to be: the pandemic makes these exceptional times; this raises the complexity of the CTL issue: and, if judges are going to get into the realm of criminal justice system funding where criticism of the government may lie, it has to be a judge who is familiar with attempts made to address the problems and understands what resources are available.

In this regard, the importance of the judicial role in its oversight of the executive was made explicit by Lord Woolf in the leading CTL authority $\left(\right.$ Gibson $\left.^{68}\right)$ :

...if Parliament willed that these should be the custody time limits, it was for Parliament also to will and provide the resources to enable courts and judges to achieve those limits. ${ }^{69}$

This dictum reinforces the importance of a judge being able to apply a rigorous level of scrutiny to situations where a lack of resources to hold trials necessitates a CTL extension. In this sense, that part of Whipple J's justification for removing HHJ Raynor, focused on the need for a judge to have sufficient experience of the system, is surely a valid one. However, not only does the claim of a need for 'some experience', beyond that of an experienced circuit judge such as $\mathrm{HHJ}$ Raynor, ${ }^{70}$ flatly contradict Whipple J's earlier statement that 'every judge in the land knows about the recovery plan' but it is equally curious that there is no evidence of similar 'removal efforts' elsewhere with judges less reproving of government.

With full knowledge that her seniority would trounce the appeal of HHJ Raynor's 'first-hand experiences at the coalface since lockdown began,, ${ }^{71}$ Mrs Justice Whipple presented an entirely different picture of the government's handling of the court crisis. ${ }^{72}$ The position taken was one of staunch optimism: 'There is a plan'. ${ }^{73}$ The learned judge felt ' $\left.\mathrm{t}\right]$ he planned steps have a prospect of success'. ${ }^{74}$ Evidence of their implementation was 'all around'. ${ }^{75}$ Trial capacity was 'being undertaken at speed and on large scale'. And although Whipple J conceded 'there is still a very great deal to do', she had 'not been persuaded that there is substance in [counsel's] criticisms of HMCTS ${ }^{\prime 76}$ nor by HHJ Raynor's assessment that 'the plan is too little too late or that there is at present a systemic failure. ${ }^{77}$

While it is correct to say that HHJ Raynor's decision was largely anomalous, ${ }^{78}$ mandated uniformity in decision-making on CTLs should cause greater alarm. ${ }^{79}$ Whereas the large majority of CTL rulings follow the 'good practice' laid down by the now-defunct Protocol, namely that the 'global pandemic is... a good and sufficient cause to extend CTLs, ${ }^{80}$ the unhesitating manner in which a

\footnotetext{
${ }^{68} R$ (Gibson) $v$ Winchester Crown Court [2004] EWHC 361 (Admin).

${ }^{69}$ Ibid, para 30, citing May LJ in R (Bannister) $v$ Guildford Crown Court [2004] EWHC 221 (emphasis added).

${ }^{70}$ Keith Raynor was appointed as a Circuit Judge based at Woolwich Crown Court from 20 April 2015, having previously served as Vice President of The Kosovo Specialist Chambers. In reviewing the available evidence in Young-Williams, Raynor was also explicit as to his experience during Covid-19: 'I balance what is said in those documents against my own personal knowledge of what has occurred in the many cases I have dealt with in the last months' (para 41).

${ }^{71} R v$ Tesfa Young-Williams, above $\mathrm{n} 47$, para 50.

${ }^{72}$ This judicial myopia among senior ranks is not unique to Whipple J. In a speech given to Mansion House on 28 July 2020, the Lord Chief Justice told his audience: 'Talk of the backlog taking years to clear is wide of the mark. The omens are good for a return to relative normality within months', published online, available at https://www.judiciary.uk/announcements/speech-by-the-lord-chief-justice-mansion-house-event-for-hm-judges/ (last accessed 11 May 2021).

${ }^{73} R \vee P$ and Others, above n 64, para 42.

${ }^{74}$ Ibid, para 43.

${ }^{75}$ Ibid.

${ }^{76}$ Ibid, para 52.

${ }^{77}$ Ibid, para 46.

${ }^{78} \mathrm{HHJ}$ Graeme Smith in $R v$ Johannessen and Others at Bolton Crown Court (4 September 2020) also refused to extend CTLs.

${ }^{79}$ The reader is forgiven if thinking it strains credulity to believe every judge agrees with each other (and, apparently, the LCJ) and that Judge Raynor is unique in being wrong.

${ }^{80} R \vee P$ and Others, above n 64, para 48.
} 
critical judicial voice was extinguished reveals how the senior judiciary is prepared to set its face against admitting the possibility of governmental ineptitude. ${ }^{81}$

A plausible corollary of the decision in $R v P$ and Others, therefore, is that CTL decisions which risk deviating from 'good practice' by non-conformity (ie presenting a negative view of the executive's response to the Covid-19 crisis) will be siphoned off to those in senior leadership roles, who, it is said, are in a more suitable position to give an appraisal of the government's efforts. The evidence suggests that the outcome here will be all 'one way'.

If Whipple J had truly been privy to a perspective unseen by HHJ Raynor, this raises additional questions relating to data transparency, allowing one to hoist the concern that information bearing crucially upon the liberty of the individual is only entrusted to the few, ${ }^{82}$ which risks offending the principle of 'open justice'. The implications of a power to encroach upon the freedom of the individual being centralised in the hands of a small circle of senior judges is not an abstract concern. Indeed, in allowing the prosecution to extend the CTL for a third time, Mrs Justice Whipple recognised that the defendant's trial would not be heard 'any earlier than January 2021' which meant the defendant would be in pre-trial detention for a total of 16 and a half months. ${ }^{83}$ On the evidence of this alone, unconvicted defendants are now being detained for periods of time that were never envisaged under the original CTL regulations by high-ranking members of the judiciary. Their charitable impression of HMCTS during Covid-19, and, concomitantly, their drive to silence the appearance of dissent, speaks to their capacity to deflect what Stephen Sedley described 'the Orwellian boot'. ${ }^{84}$ While politically convenient, Whipple J's rejection of the contention that systemic failure has befallen criminal justice will make future challenge to CTL extensions highly unlikely to succeed, casting further systemic uncertainty over the already weakened position of defendants and a pall over the once venerated, but now vulnerable, presumption of innocence.

\section{Judicial mismanagement of CTL procedures}

In this section it will be argued that the approach endorsed in $R v P$ and Others, allowing for the substitution of an experienced circuit judge with a High Court judge, is not only misconceived for the reasons discussed but also risks introducing harmful inconsistency on fundamental principles that apply to CTL extensions.

In this regard, Whipple J's claim that 'some experience of running the criminal courts gained from being a presider' was needed for a CTL extension hearing and therefore legitimated the removal of HHJ Raynor from his own, flies in the face of the approach laid down by the CTL authorities requiring that evidence is given on oath by HMCTS when a determination is being made as to the adequacy (or otherwise) of its efforts in managing the case flow of criminal courts. It is submitted that this approach is the correct one to take, thereby aiding any evidential gap that may arise with judges considered to have less experience of running courts during Covid-19. The existence of legal authority on this point aside, to argue otherwise would lead to the non-sensical inference that the vast majority of judges in England and Wales lacked the capability to review and decide upon testimonial evidence, calling into question their very competence more generally.

That said, the line of authority spelling out the correct procedure to be taken on this matter has compelling force on its own. In delivering his damning indictment of the government's handling of the criminal justice system during Covid-19, HHJ Raynor drew attention to a series of cases, two

\footnotetext{
${ }^{81}$ Mrs Whipple gave extended shelf-life to the spirit of the Protocol when she said: 'I note that the direction from the PQBD and SPJ by which that Protocol was withdrawn specifically states that decisions henceforth should be made "with the restricted availability of courts an important factor"' (original emphasis). She added ' $\mathrm{t}$ ] he availability is restricted because of the effects of the pandemic; the pandemic has not gone away; we are now just having to manage with it and despite it': $R v$ $P$ and Others, above n 64, para 49.

${ }^{82}$ On the dangers to freedom that stem from closely guarded judicial-executive relations, see McConville and Marsh, above n 59.

${ }^{83}$ In custody from 27 August 2019.

${ }^{84}$ S Sedley 'Law and state power: a time for reconstruction' (1990) 17 Journal of Law \& Society 234 at 239.
} 
of which are of importance here: $R$ (McAuley) $v$ Crown Court at Coventry (Practice Note) $)^{85}$ and $R$ (Raeside) $v$ Crown Court at Luton. ${ }^{86}$

McAuley is instructive not least because of the explicit terms in which the issue of resource constraints impinging upon the custody period was discussed:

It is clear from the basis of ex parte McDonald that it is for the Prosecution to satisfy the court of the need to extend CTL. It must follow that evidence from the senior management of HMCTS must be provided well in advance of the hearing to the defendant and adduced by the CPS to the court. The judge must then subject the application and the evidence to that rigorous level of scrutiny which is required where a trial is to be delayed and a person confined to prison because of the lack of money to try the case. ${ }^{87}$

The President of the Queen's Bench Division went on to say if there were a systemic problem with courtroom availability, the Secretary of State must amend the regulations and seek the approval of parliament:

If that is not done, the court has no option but to apply the present CTL and HMCTS must find the necessary money or face the prospect of a person who may represent a danger to the public being released pending trial. ${ }^{88}$

Similarly, Raeside confirmed where a lack of a courtroom was a reason given for a CTL extension being necessary, the court needed to hear evidence on oath. ${ }^{89}$

In skirting any need 'to give HMCTS the opportunity to answer those criticisms before coming to any conclusions', Whipple J instead drew upon her own experience ${ }^{90}$ to fill the 'evidential gap' ${ }^{\text {,91 }}$ and, in noting that counsel for the defence (P) had argued that it was 'for the CPS to invite HMCTS to participate ${ }^{92}$ remarked dismissively: 'I am not so sure about that'. ${ }^{93}$ To explain her doubt as to the issue Whipple J continued:

After all, it is P, not the CPS, who submits that HMCTS has failed in its obligations under domestic and Convention law and it is $\mathrm{P}$ who raises the issue on which HMCTS is entitled to give its answer. Thus, this situation is very different from that which arose in $R$ (McAuley) $v$ Crown Court at Coventry [2012] EWHC 680 (Admin), [2012] 1 WLR 2766 on which Ms Forshaw relies. But I do not need to decide the point and I simply record it for future determination, if that is necessary. ${ }^{94}$

The reasoning employed here, which implies that the validity of the ratio from McAuley in this context is baseless, represents a worrying example of judicial obfuscation in an area of the law that, fundamentally, dilutes defendant protections. Remarkably, this interpretation of a leading CTL authority

\footnotetext{
${ }^{85}$ [2012] EWHC 680 (Admin).

${ }^{86}$ [2012] EWHC 1064 (Admin).

${ }^{87}$ McAuley, above n 85, para 35.

${ }^{88}$ Ibid.

${ }^{89}$ Raeside, above n 86 , para 33 .

${ }^{90}$ Whipple J stated: 'I am most familiar with the 14 crown courts in the South East outside London and I use that part of the country as an example': $R v P$ and Others, above n 64, para 43.

${ }^{91}$ With respect, the evidence upon which Whipple J determined that there were sufficient courts and staff was thin from a legal standpoint. As to plans said to 'have a prospect of success' it was conceded these 'have not yet come to fruition, and much will depend on when and how that occurs' (para 46). Nor was evidence offered in support of the conclusion that increased trial capacity was 'being undertaken at speed' (para 46).

${ }^{92} R v P$ and Others, above n 64, para 52.

${ }^{93}$ Ibid.

${ }^{94}$ Ibid.
} 
rests on a misconception. In McAuley it was the prosecution seeking a CTL extension having been notified by the Court that there was no judge and/or courtroom available. The Divisional Court did not say it was therefore the defence's responsibility to call evidence to prove that HMCTS were at fault or that there was a systemic failure, nor should it be. In any event, the practicalities of this alone render the burden being placed on the defence unworkable, although this, in the scheme of relevant considerations, is low down.

The prospect of an accused's freedom being overridden by misinterpretation of the law is as concerning as it is surprising, not least because it comes from a senior member of the judiciary who outflanked a circuit judge in his own case on the ground that they were the more appropriate person to handle such matters. This leads to a further powerful argument why having the most senior judges in exclusive control of decision-making in the arena of CTLs is, counter-intuitively, problematic.

Bearing in mind that Mrs Justice Whipple is one of the four presiders on the South East Circuit, to say the Criminal Courts Recovery Plan is not her 'cause' is to downplay her key role in how the courts have functioned during the Covid-19 crisis. In light of Whipple J's leadership position, one might be forgiven for struggling to envisage how a judge associated with the administration of justice at the level she operates would ever 'conclude that the position has become one where there is a systemic failure to be able to provide for trials within the custody time limits. ${ }^{95}$

It is no surprise, therefore, that there is scant regard in $R v P$ and Others given to the need to call evidence as to the efficacy of the government's plans which could be tested. Instead, observations aimed at those involved in keeping the courts running were couched in affirmative language. The manner in which serious legal argument, bearing upon the liberty of the individual, is glided over ('I do not need to decide the point'), in exchange for approbation for the wider system underscores the undesirable tension now permeating the CTL regime which arises from a judicial approach that feels more akin to a self-certification process ('...if I had found any attraction in [defence counsel's] submissions, I would have felt it necessary, as a matter of basic fairness, to give HMCTS the opportunity to answer those criticisms'). ${ }^{96}$ With no judicial will on display in $R e P$ and Others to require a full examination of evidence from HMCTS on oath, it would appear fanciful to imagine that the predicament of unconvicted defendants facing long-distanced trial dates will improve.

In spite of this, affording circuit judges the authority to rule upon CTL extensions is surely sensible, transparent and a fair contingency where links between the senior judiciary and HMCTS mean impartiality may be seen to be open to doubt. From a practical standpoint too, widening the pool of judges to oversee a commonplace (but vital) aspect of the criminal process would relieve pressure from the upper ranks of the judiciary at a time when workloads have been intensified by the backlog crisis in the courts. As such, the current move to restrict those with standing to hear CTL applications to a coterie of senior judges, as appears to be the direction of travel following $R v P$ and Others, is an irrational one.

\section{A line in the sand: $\mathbf{R} v$ Woolwich $C C$, ex $p$ DPP}

Developments since $R v P$ and Others show that the Senior Judiciary have helped reduce, if not eliminate, governmental accountability for the criminal case backlog. Despite Whipple J's best efforts to dampen the impact of Young-Williams by presenting an 'informed' perspective of HMCTS's efforts to alleviate the backlog during the pandemic, in contradistinction to that of HHJ Raynor, the High Court judge did not explicitly reject Young-Williams as having no authoritative status (the matter at hand being a CTL extension application rather than a legal challenge on the substantive content of Judge Raynor's decision).

Instead, this task was left to the DPP who pursued a claim for judicial review of HHJ Raynor's finding of systemic failure in the court system, with HMCTS being principally at fault. The Divisional

\footnotetext{
${ }^{95} \mathrm{R} v$ P and Others, above $\mathrm{n}$ 64, para 39, citing Latham LJ in $R$ (Kalonji) $v$ Wood Green Crown Court [2007] EWHC 2804 (Admin), para 18.

${ }^{96} R \vee P$ and Others, above n 64, para 52, emphasis added.
} 
Court's judgment in $R v$ Woolwich CC, exp DPP ${ }^{97}$ (exp DPP) that followed is significant in this context because it represents the Senior Judiciary seeking to draw a line under the matter of Young-Williams, in a way that curtails examination of the government's management of criminal courts during the pandemic.

The judgment's importance in this respect is two-fold. First, for its declaration that HHJ Raynor's decision was unlawful. Secondly, for the manner in which it sets out guidance on the future approach to be taken at CTL applications during the pandemic. On this first point, it is important to underscore that the argument made here does not depend on the substantive issue, ie whether the government's efforts during Covid-19 are 'too little too late'. ${ }^{98}$ As will be discussed, this latest development does not detract from the wider points raised here as to the integrity of judicial decision-making under the CTL regime and, concomitantly, threats to the presumption of innocence.

By way of summary, the LCJ (sitting with Holroyde LJ) took issue with HHJ Raynor's position on the difficulties surrounding the CTL regime, namely that 'at the heart of the problem in restarting and then increasing the volumes of jury trials was a lack of funding by HMCTS and the Ministry of Justice'. 99 They therefore rejected Judge Raynor's finding that underfunding had resulted in 'broad systemic failure by both to provide for jury trials within CTLs'. ${ }^{100}$ It was explained that Judge Raynor had erred in two main respects. As to the issue of funding, HHJ Raynor had misunderstood that ' $[t]$ he problems in accelerating the capacity of the system to hold jury trials have been practical and logistical, rather than financial, ${ }^{101}$ a finding supported by, it was said, 'materials publicly available describing the efforts made by the Working Group and HMCTS to get jury trials up and running after lockdown at the end of March 2020, ${ }^{102}$

Respectfully, this dismissive reasoning masks the uncomfortable truth that successive governments over the past decade have systematically stripped all spare capacity out of the justice system, leaving the dwindling criminal court estate woefully under-resourced during the pandemic. The Court's unwillingness to recognise the nexus between historic underfunding and current courtroom capacity is, accordingly, more than questionable.

As to the matter of Judge Raynor's judicial method in determining that governmental efforts to resolve the criminal court backlog were inadequate, the learned judges were critical of his reliance on 'material which has not been subject to any evidence or argument'. ${ }^{103}$ Ex $p$ McDonald makes clear here that evidence will not always be necessary in CTL applications; rather, '[w]hether evidence will be necessary, or whether the court can rely on information supplied by counsel, will depend on the nature and extent of any controversy... It is, however, always for the court and not for the parties to be satisfied'. ${ }^{104}$ In this regard, it is submitted that the Court in ex $p$ DPP did not give sufficient weight

\footnotetext{
${ }^{97}$ [2020] EWHC 3243 (Admin). The hearing was held on 4 November 2020. Judgment was handed down on 26 November 2020. Tesfa Young-Williams, HMCTS and the Lord Chancellor were listed as Interested Parties.

${ }^{98} R$ v Tesfa Young-Williams, above $\mathrm{n} 47$, para 47.

${ }^{99}$ Ex $p$ DPP, above n 97, para 45.

${ }^{100}$ Ibid.

${ }^{101}$ Ibid, para 38, emphasis added. Their lordships also explained HHJ Raynor's 'focus on funding was infected by a misunderstanding of article 6 of the European Convention on Human rights' (at 47) and his reliance on Zimmermann $v$ Switzerland (1983) 6 EHRR 17 misplaced. That judgment states: '...a temporary backlog of business does not involve liability on the part of the Contracting States provided that they take, with the requisite promptness, remedial action to deal with an exceptional situation of this kind', para 29. It is submitted that it is misleading to describe the backlog affecting criminal courts in this jurisdiction as 'temporary;' rather, it has become endemic to the system, on which, see B Quinn 'Case backlog threatens criminal justice system in England and Wales, say inspectors' (The Guardian, 19 January 2021). Moreover, while their Lordships were correct in stating that this ECtHR decision does not provide authority for a 'regardless of cost' test, any 'measures taken are assessed as to their effectiveness' and 'whether they have been taken in good time' (Van Dijk, above n 9, p 595). On the wider problems of interpreting Art 6 ECHR, see R Goss Criminal Fair Trial Rights: Article 6 of the European Convention on Human Rights (London: Hart Publishing, 2014).

${ }^{102}$ Ex p DPP, above n 97, para 47.

${ }^{103}$ Ibid, para 50.

${ }^{104}$ Ex p McDonald, above n 13, at 846.
} 
to the pressing predicament in which HHJ Raynor found himself; the prosecutor who had attended the CTL hearing in Young-Williams did so '[w]ithout evidence from an HMCTS senior manager'. ${ }^{105}$ Plainly, this was not a hearing that could be further adjourned to await evidence, without the CTL threshold being passed.

Furthermore, bearing in mind that the liberty of a legally innocent defendant was at stake, HHJ Raynor's self-directed efforts to determine whether continued detention was lawful in the absence of any evidence from HMCTS was arguably in line with his obligations under the Criminal Procedure Rules (CrimPR). ${ }^{106}$ This line of argument operates on the basis that a judge, when addressing his mind to the question of bail (with which there is procedural overlap with the POA 1985, discussed above), is subject to the 'overriding objective' (rule 1.1) which mandates that all parties (including the judge) ensure 'appropriate information is available to court' (rule 1.1.(2)(f)), including where there has been a 'significant failure' (rule 1.2.(1)(c)) of one party to comply with the CrimPR. ${ }^{107}$

In turning to the second notable and interlinked aspect of ex $p D P P$, the position canvassed throughout this paper as to the requirement of evidence in CTL hearings was endorsed by the LCJ: custody decisions must be based on evidence led by the prosecution (in this context sourced from HMCTS). Yet in spite of the authoritative restatement of the CTL case law on this central point, the liberty of untried defendants under the CTL regime remains precarious. Within the same breath, the LCJ removed the requirement of evidence altogether on the specific issue of the performance of government in ensuring adequate court capacity during the health crisis, when he stated:

No formal evidence about the impact of the pandemic will be needed in the light of the publicly available material and this judgment. All parties can be expected to be familiar with the steps taken to date by HMCTS and the courts. ${ }^{108}$ (emphasis supplied)

This judgment therefore cements the effect of the original Protocol to the extent that delay attributable to the pandemic, which means that it is neither practicable nor safe to hold a trial within the CTL, provides a 'good cause' to extend the period. The upshot of this is that the ability of defence counsel to forensically examine the government's management of criminal courts during the pandemic has been neutered.

It is of further concern that the LCJ's declaration in exp DPP is premised on the empirically unsound notion (one mirrored by Whipple $\mathrm{J}$ in $R v P$ and Others) ${ }^{109}$ that the government's efforts to lessen the problem of courtroom capacity are universally felt. As the criminal courts' own rulings attest, ${ }^{110}$ regional differentials of government strategy exist, with some court circuits less affected than others, demonstrating that a blanket approach is as objectionable as it had become under the Protocol. Where ex $p$ DPP differs from that early instrument, is on the second limb of the POA 1985, s 22(3)(a)(iii).

To mitigate the harshness that inevitably results from untried defendants being subject to automatic prolonged custody extensions, the LCJ stipulated: '[w]hether it provides a sufficient cause depends on an examination of the individual facts of the case and of the defendant in question'. ${ }^{11}$ In making this assessment, the judgment provides a list of factors for judges to take into account

\footnotetext{
${ }^{105} R$ v Tesfa Young-Williams, above $\mathrm{n} 47$, para 18.

${ }^{106}$ The latest iteration of which is the 2020 Rules, SI 2020/759.

${ }^{107}$ This point was not explored by their lordships because, on their view, 'Judge Raynor did not need to decide the matter because quite separately he concluded that the CPS had not acted with due diligence and expedition': ex $p$ DPP, above n 97, para 55.

${ }^{108}$ Ibid, para 44.

${ }^{109}$ Although the High Court judge declared that there was a national response to the backlog crisis, her judgment places heavy reliance on her experience of ' 14 crown courts in the South East outside London': $R v$ P and Others, above n 64, para 43.

${ }^{110}$ See eg $R v$ Johannessen, above $\mathrm{n} 78$, which details comparative successes and failures in government strategy between regions.

${ }^{111}$ Ex p DPP, above n 97, para 44.
} 
(eg 'the likely duration of the delay before trial; whether there has been any previous extension of the CTL' and the 'likely sentence in the event of conviction').

Although, then, the approach following ex $p$ DPP might offer some greater hope that unconvicted defendants will be released on bail, the 'non-exhaustive principles' offered by the LCJ appear to add little, if anything, to the discretionary power already available to those adjudicating upon CTL extensions. Their impact is also heavily conditioned by the prospect that pre-selected panels of judges more executive-aligned in disposition will be making such far-reaching determinations. ${ }^{112}$

\section{Conclusion}

Nobody can seriously contest the heavy strain the worldwide health emergency has had on the justice system, especially with mass restrictions placed upon jury trials. At the same time, pursuit of criminal conviction should not blind us to other core values and principles of the criminal process, not least its bedrock: the presumption of innocence. The burning issue of extending CTLs during Covid-19 provides a cautionary tale in this regard. To the human cost of the crisis in terms of death and illness can be added the human cost in terms of unconvicted defendants languishing in detention without a trial date in sight, often in abysmal conditions injurious to physical and mental health. ${ }^{113}$

As is acknowledged throughout, the court system finds itself in an unprecedented situation. However, it is submitted that the wholly exceptional backdrop to these arguments works both ways. Whilst on the one-hand, the state of pandemic could be said to justify further, lengthy detention, on the other, the right of an unconvicted accused to liberty may be argued to assume maximum importance. Yet recent intervention by the senior judiciary on this issue has, in turn, enfeebled the right to freedom. When ruling upon CTL applications there has been a concerted reluctance among judicial leaders to stare empirical truth in the face; yet the concerted steps it does take shore up the government's contribution to the 'backlog crisis' and its (mis)handling of the Covid-19 crisis, shielding it from criticism of inordinate and endemic delays. These delays are an integral cause of trial dates being pushed increasingly further back than the regime was ever designed for.

All the present indications are that social distancing measures and restrictions will be in place for some considerable time and will continue to affect jury trials. Even with the best spirit of optimism, the fall-out from the pandemic is not going to resolve itself in the short or medium term. ${ }^{114}$ The case backlog confronting the criminal courts is of such a scale that the arguments canvassed here will continue to resonate, long after the correct vaccine is widely available. ${ }^{115}$ In recognition of this reality, there needs to be acceptance from the courts that it is neither reasonable nor responsible to keep adjourning unproven criminal matters to a notional future time with defendants - all of whom remain legally innocent - in custody. The use of CTL extensions to mitigate system delay is, categorically, the wrong vaccine for its own afflictions.

\footnotetext{
${ }^{112}$ One has to question the underlying rationale of this new category of CTL judges, if the LCJ is of the view that '[a]ll parties can be expected to be familiar with the steps taken to date by HMCTS and the courts': ex $p$ DPP, above n 97, para 44.

${ }^{113}$ For an official account, see HM Chief Inspector of Prisons Annual Report (2018-19).

${ }^{114}$ Devi Sridhar, one of Britain's foremost experts on global health has voiced that the crisis may extend as far as 2024: A Gregory and T Allen-Mills 'When will coronavirus end?' (The Times, 10 October 2020).

${ }^{115}$ Sir Michael Barber has advised that 'getting to 80 per cent global coverage generally takes about 30 years. For example, the Rotavirus vaccine was first made available in 2006; 15 years later, global coverage is at 37 per cent. We are now attempting to deliver a vaccine ten times faster, to ten times more people, with ten times the complexity of any previous vaccination programme': 'Every nation needs to prepare for a Covid vaccine now' (The Times, 9 October 2020).
}

Cite this article: Marsh L (2021). The wrong vaccine: custody time limits and loss of liberty during Covid-19. Legal Studies 41, 693-709. https://doi.org/10.1017/lst.2021.27 